\title{
Pelvic lymph node dissection in high-risk prostate cancer
}

\author{
Luciano Haiquel ${ }^{1}$, Xavier Cathelineau ${ }^{2}$, Rafael Sanchez-Salas ${ }^{2}$, Petr Macek ${ }^{2}$, Fernando Secin ${ }^{3}$ \\ ${ }^{1}$ Department of Urology, Sanatorio Las Lomas de San Isidro, Buenos Aires, Argentina; ${ }^{2}$ Department \\ of Urology, L'Institut Mutualiste Montsouris, Université Paris Descartes, Paris, France; ${ }^{3}$ Discipline of \\ Urology, Universidad de Buenos Aires, Argentina
}

\section{ABSTRACT}

Introduction: The therapeutic role of pelvic lymph node dissection (PLND) in prostate cancer (PCa) is unknown due to absence of randomized trials.

Objective: to present a critical review on the therapeutic benefits of PLND in high risk localized PCa patients.

Materials and Methods: A search of the literature on PLND was performed using PubMed, Cochrane, and Medline database. Articles obtained regarding diagnostic imaging and sentinel lymph node dissection, PLND extension, impact of PLND on survival, PLND in node positive "only" disease and PLND surgical risks were critically reviewed.

Results: High-risk PCa commonly develops metastases. In these patients, the possibility of presenting lymph node disease is high. Thus, extended PLND during radical prostatectomy may be recommended in selected patients with localized high-risk PCa for both accurate staging and therapeutic intent. Although recent advances in detecting patients with lymph node involvement (LNI) with novel imaging and sentinel node dissection, extended PLND continues to be the most accurate method to stage lymph node disease, which may be related to the number of nodes removed. However, extended PLND increases surgical time, with potential impact on perioperative complications, hospital length of stay, rehospitalization and healthcare costs. Controversy persists on its therapeutic benefit, particularly in patients with high node burden.

Conclusion: The impact of PLND on biochemical recurrence and PCa survival is unclear yet. Selection of patients may benefit from extended PLND but the challenge remains to identify them accurately. Only prospective randomized study would answer the precise role of PLND in high-risk pelvis confined PCa patients.

\section{ARTICLE INFO}

Luciano Gabriel Haiquel https://orcid.org/0000-0002-9083-8346

\section{Keywords:}

Prostate cancer, familial

[Supplementary Concept];

Lymph Node Excision; Lymph

Int Braz J Urol. 2022; 48: 54-66

Submitted for publication:

December 15, 2020

Accepted after revision:

January 22, 2021

Published as Ahead of Print:

February 28, 2021

\section{INTRODUCTION}

PCa is the second most frequent malignancy in men worldwide (1) and most patients have low-risk features $(2,3)$. However, 15\% of men develop high-risk PCa and are more likely to metastasize and die from disease (4). Although patients with low-risk prostate cancer have a greater benefit with radical prostatectomy, a subset of patients with high-risk prostate cancer appears to benefit from surgical treatment (5).

The AUA/ASTRO/SUO guideline recommends radical prostatectomy as one of the standard treatments in this group and this should be 
accompanied by PLND assuming an estimated 15-40\% LNI rate (6). PLND candidates may be selected based on clinical information such as serum PSA levels, Gleason score and estimated tumor volume $(5,7)$.

Memorial Sloan Kettering Cancer Center (MSKCC) and Briganti have developed nomogra$\mathrm{ms}$ to predict LNI in patients with localized PCa $(6,8)$. The EAU-ESTRO-SIOG and NCCN guidelines $(1,2)$ recommend the use of these predictive tools to select candidates for PLND. Of all the validated models, the Briganti and MSKCC nomograms were identified as the most accurate models available to predict LNI and have been validated by several authors showing comparable results $(9,10)$. However, some guidelines indicate that Partin tables and Roach formula could be useful as well (9).

Guidelines recommendations to select patient for PLND are not uniform. The European Urological Association (EAU) recommends PLND in patients with LNI risk $>5 \%$ as per Briganti's nomogram $(2,11)$, while the AUA guidelines establish a $2 \%$ risk cut-off $(12,13)$.

Although extended PLND (ePLND) still represents the most accurate method for staging pelvis confined $\mathrm{PCa}(2)$, its therapeutic benefit is still unclear as ePLND increases surgical time and perioperative complications (14).

\section{MATERIAL AND METHODS}

This critical review complied with some Amstar checklist criteria. We included PubMed, Cochrane, and Medline publications in the English language. Each subheading of this manuscript was framed and discussed according to "PICO" (population, interventions, control groups and outcomes) principles. The authors verified in detail title, abstract, full text and data extraction of studies under review.

We included several retrospectives studies, reviews, comparative studies with at least one control arm and one meta-analysis. Comparative single-center cases and one ongoing clinical trial were included as well. Single case series, case reports, reviews, and editorial comments were excluded.
Limitations of this study included lack of statistical analysis of crude data base information from different publications. In addition, this critical review includes retrospective studies as well. All authors deny conflicts of interest (Figure-1).

Patient selection: diagnostic images and sentinel lymph node dissection

Unfortunately, the accuracy of routine images such as computed tomography or magnetic resonance imaging (MRI) to identify LNI is poor (15). Although increased node size is specific for LNI, its sensitivity is low (32\%) as normal size nodes can harbor small foci of metastatic disease (16).

A synthetic ultrasmall superparamagnetic iron oxide composed of dextran-coated iron oxide nanoparticles known as Ferumoxtran-10 accumulates in non-cancerous lymphatic tissue, and has been used as a molecular MRI contrast agent. The administration of ferumoxtran-10 during MRI (17-20) has shown reliable differentiation of benign from malignant nodes, reaching a negative sensitivity and predictive value of $82 \%$ and $96 \%$ respectively (15). However, these studies have been limited by the low number of patients.

Although molecular imaging has emerged as a promising technique for improved lymph node staging in patients with $\mathrm{PCa}$, positron emission tomography (PET) tracers like F18- or C-11-choline have not proved to be superior to anatomical imaging methods $(20,21)$ and a prospective study with C-11 choline PET/CT has shown disappointing results (22).

That said, some reports have shown encouraging data with PSMA PET/CT for initial detection of LNI. Recently, Ga-68 PSMA PET/CT has been proposed for the evaluation of biochemical recurrence after primary active treatment of $\mathrm{PCa}$. Several studies have shown high diagnostic performance with a higher sensitivity compared to other radiopharmaceuticals such as radiolabeled choline $(23,24)$. However, a recent meta-analysis concluded that radiolabeled PSMA PET/CT shows a moderate sensitivity and high specificity for detection of metastasis and further studies would be necessary to substantiate the diagnostic accuracy of PSMA PET/TC for this purpose (25). Nonetheless, preoperative LN staging with 68Ga PSMA 
Figure 1 - Flowcharts

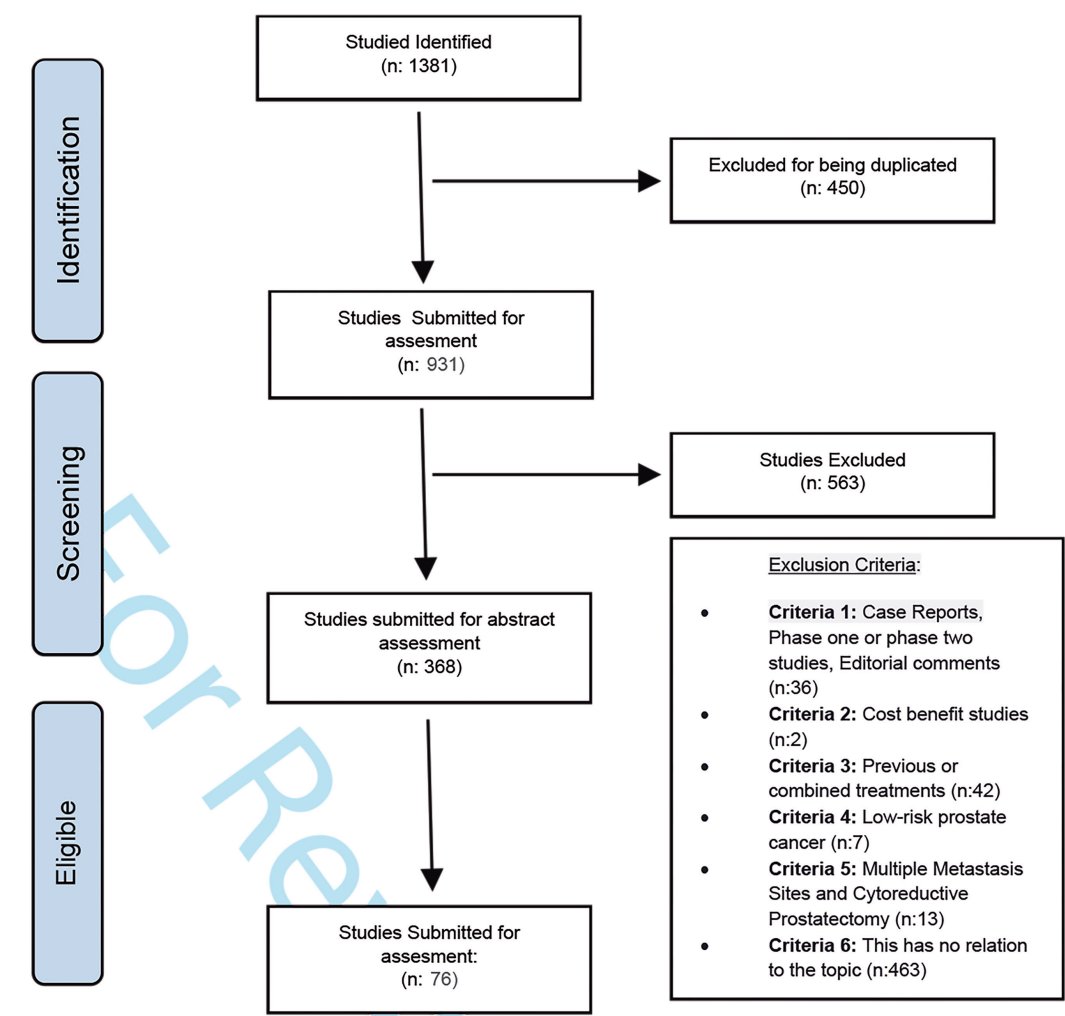

PET proved to be superior to standard routine imaging in patients with intermediate to high-risk PCa (26). In the absence of compelling evidence, its high costs and widespread inapplicability limit its routine use.

Increasing body of literature shows the utility of intraoperative PET gamma probes to detect LNI in head and neck, breast and endometrial cancers (27-30). Though promising, its benefit in prostate cancer surgery remains to be determined (31).

Since the initial works of Wawroshek et al. on sentinel lymph node dissection (SLND) in PCa (32) in 1999, there is still no consensus on its definition, technique, diagnostic role and utility. During a consensus group meeting on SLND, experts agreed that All nodes that appear first in each drainage basin seen early on (15 minute) lymphoscintigrams and/or single-photon emission
CT imaging in new basins that were not yet seen on the early images" correspond to sentinel node (33). Experts also agreed on the potential utility of tracers with green indocyanine and a hybrid marker of technetium-99m nanocolloid (99mTc/ green indocyanine) administered transrectally with a time interval ranging from 8 hours to 30 minutes before surgery according to the marker implemented (33). In a retrospective study, using data from 130 patients with intermediate to high-risk PCa, researchers found an estimated overall median sensitivity of $95.2 \%$, which is promising and appears to be nearly twice as high as the average sensitivity reported for $11 \mathrm{C}$ - and $18 \mathrm{~F}$-choline and 68Ga-PSMA PET/CT (26).

Wit et al. reported that sentinel node biopsy (SNB) in PCa has almost equivalent diagnostic accuracy to ePLND, and recommends 
combining SNB with ePLND in high-risk disease (34). However, the false negative rate of SNB may range from $4.1 \%$ to $25 \%$ (35), and this highlights the importance of combining both procedures to improve staging.

Despite vast improvements in imaging studies, their combination with SNLD has been proposed to improve LND results. However, there is a need to define, optimize and standardize the technique for widespread applicability. PLND currently represents the gold standard for evaluating the presence of LNI.

\section{Lymphadenectomy, limited or extended?}

While there is no unified definition, the EAU PCa Guideline Panel categorized PLND extension as (14) (Figure-2):

1. None;

2. Limited (IPLND): obturator nodes;

3. Standard (sPLND): obturator and external iliac nodes;

4. Extended (ePLND): obturator, external, and internal iliac nodes;

5. Super-extended (sePLND): ePLND plus common iliac, presacral, and/or other nodes;

6. Undefined or unclassified.

\section{Figure 2 - Anatomical areas for the definition of the extent} of dissection.

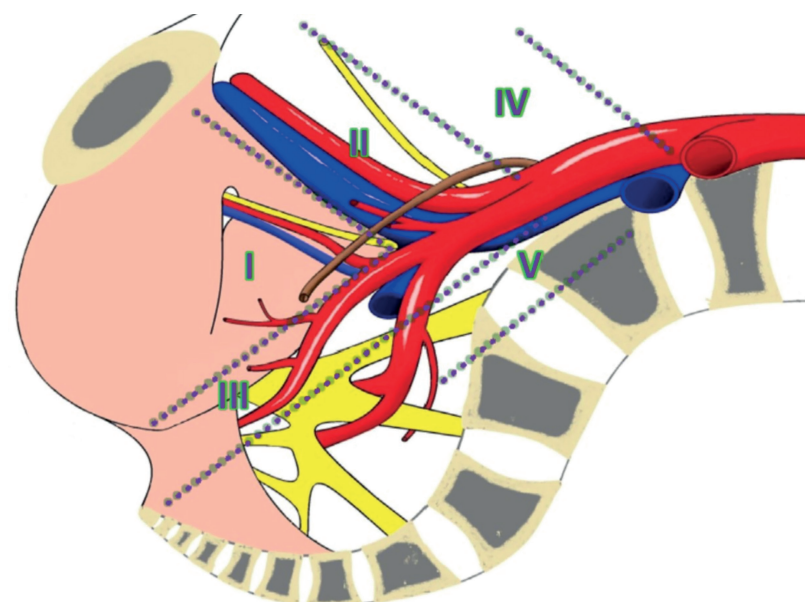

I = obturator nodes; $\mid I$ = external iliac nodes; III = internal iliac nodes; IV = common iliac nodes; $V$ = presacral nodes (14).
LNI rate seems to be related not only to disease biology but also to the extent of PLND. Several studies suggest there is a positive correlation between extent and number of pelvic nodes examined and metastatic burden (36-38).

In an attempt to establish the minimum number of nodes required during a prostatectomy, Barth et al. (39) recommended removing at least 13 nodes during sPLND. Interestingly, LNI rate doubled when more than 12 lymph nodes were examined. In addition, tissue work up method and handling by the pathologist appeared as an important factor for LNI diagnosis.

Briganti et al. (36) found that the possibility of detecting LNI was close to zero when less than 10 lymph nodes were removed in patients with a LNI risk $\geq 2 \%$ undergoing a PLND with a template that included the external iliac, obturator, and hypogastric lymph node packets. The authors provided a critical assessment of the concept that nodal yield at PLND is closely associated with LNI rate.

Abdollah et al. also estimated a count of 20 LNs for optimal pelvic lymph node staging in $\mathrm{PCa}$ as it renders a 10\% false negative rate regardless of tumor characteristics (40). Heidenreich et al. recommended ePLND after they found that excluding internal iliac LND during PLND would leave behind 25\% of all positive LNs (41). Their study also indicated close relationship between the number of LN removed and the long-term oncological outcome.

Weingärtner K et al. (42) performed sPLND on 30 human cadavers and 59 consecutive patients with clinically organ confined PCa during radical retropubic prostatectomy. PLND technique was performed in exactly the same manner in the human cadavers as in patients undergoing radical prostatectomy. The authors compared node count, size and distribution of all removed lymph nodes for each anatomical region in both groups. They concluded that approximately 20 pelvic lymph nodes would be an adequate sample size during a sPLND.

Mattei A. et al. informed that removal of LN around external iliac, hypogastric, obturator and common iliac LNs up to the ureteric crossing 
would remove approximately $75 \%$ of all nodes potentially harbouring metastasis (43).

Nodal metastases do not follow a predefined route, which is why, the more extended the PLND the higher the likelihood of metastases identification. Therefore, PLND should be as thorough as possible when clinically indicated.

What is the impact of plnd on survival?

Literature is controversial and no adequate study has been developed to answer this question. Although several retrospective studies support the notion that ePLND may increase survival in high-risk PCa (44-48), recent results of a single institution double-arm prospective phase III study indicated the opposite. The authors found that ePLND had no impact on relapse and cancer specific survival (CSS). Table-1 summarizes the results of most recent publications.

In a systematic review, Fossati et al. evaluated 21 retrospective studies analysing the impact of PLND on oncologic outcome. The authors included 18 studies evaluating biochemical recurrence and six looking into survival in intermediate and high-risk PCa patients. This meta-analysis failed to demonstrate a therapeutic benefit of PLND (14).

In addition, several current retrospective studies have criticized the impact of PLND on survival. In one of them, 20.668 Surveillance, Epidemiology, and End results (SEER) database patients with PCa and >5\% LNI risk as per Briganti's nomogram were evaluated. This study compared radical prostatectomy with and without PLND. No significant difference of CSS and overall survival (OS) was found between groups (5-year CSS rate: 99.4\% vs. 99.7\%, $\mathrm{p}=0.479$, 5-year OS rate: $97.3 \%$ vs. $97.8 \%, p=0.204)$. They concluded that neither PLND nor its extension was associated with improved survival in these patients and perhaps the cut-off point of 5\% is too low to show benefits in patients who underwent PLND along with the prostatectomy (50).

Preisser et al. compared oncologic outcomes of 9.742 intermediate and highrisk patients who underwent radical prostatectomy with or without PLND. The authors did not find significant differences in BCR (51).
Conversely, again Preisser et al. evaluated cancer specific mortality (CSM) in 28.147 SEER database PCa patients (2004-2014) subject to eLPND or IPLND. They found a lower CSM in patients who underwent eLPND. They estimated that removal of $>11$ nodes during PLND improved 6 -year CSS and each additional LN removed reduced CSM risk by $4.5 \%$ (44).

In a retrospective meta-analysis involving 1.095 intermediate and high-risk PCa patients of 3 centers in Korea, Min Soo Choo et al. (46) suggested ePLND would provide oncological benefits by preventing biochemical relapse (BCR). The pooled analysis showed a significant reduction in $\mathrm{BCR}$ with ePLND compared to sPLND (HR 0.71, 95\% CI 0.56-0.90, $\mathrm{p}=0.005$ ).

An additional meta-analysis on 5 retrospectives studies (45), found improved BCR with ePLND, although two of them also included low-risk patients. Sood et al. recently evaluated 311.061 patients from the National Cancer Database (NCDB). They found that patients undergoing ePLND had 9\% lower risk of 10-year mortality as compared to patients undergoing none or limited PLND (48).

Recent results of the only prospective phase III trial were presented. To define the primary endpoint, the authors compared biomedical recurrence-free survival (BRFS) among 300 patients with D'Amico's intermediate or high-risk PCa, who had received IPLND (n 150) or ePLND (n 150) during robotic prostatectomy. This trial was designed with $80 \%$ power and an alpha error of 0.05 to detect a 15\% difference in 5-year BRFS. ePLND and IPLND yielded median (mean) 17 (19.8) and 3 (4.1) positive nodes, respectively $(\mathrm{p}<0.001)$, while ePLND resulted in five times more lymph node metastases detection ( $\mathrm{p}<0.001)$. However, over a median follow-up of 61.4 month the authors found no difference in BRFS (HR 0.91, 95\% CI 0.63 - 1.32, p=0.6), distant metastases or death between groups (48). Although the primary endpoint has not been reached, a short time subgroup analysis suggests a benefit in BRFS for patients who underwent ePLND diagnosed with preoperative biopsy International Society of Urological Pathology (ISUP) grade groups 3-5 (HR 0.33, 95\% CI 0.14-0.74, interaction $\mathrm{p}=0.007$ ) (49). 
Table 1 - Baseline characteristics for studies addressing: Author and Study Date, type of study, numbers of patients and Features, surgical route, D'amico Risk or Gleason score, PSA and reports on oncologic outcomes.

\begin{tabular}{|c|c|c|c|c|c|c|c|}
\hline $\begin{array}{l}\text { Author, Study Date. } \\
\text { Type of study }\end{array}$ & $\begin{array}{l}\mathrm{N}^{\circ} \text { of Patients } \\
\text { and Features }\end{array}$ & Treatment & $\begin{array}{l}\text { Surgical } \\
\text { route }\end{array}$ & $\begin{array}{l}\text { D'amico Risk or } \\
\text { Gleason score }\end{array}$ & PSA & $\begin{array}{l}\text { Outcome reported } \\
\text { on }\end{array}$ & $\begin{array}{l}\text { Oncologic } \\
\text { outcomes }\end{array}$ \\
\hline $\begin{array}{l}\text { Fossati, et al. (2017). } \\
\text { Retrosperctive study. } \\
\text { (Meta-analysis) } \\
\text { Oncological outcomes } \\
\text { by } 29 \text { studies (14). }\end{array}$ & $\begin{array}{l}\text {-Experimental arm } \\
\text { and one control } \\
\text { arm; } \\
\text { Studies with more } \\
\text { than two arms } \\
\text { T1-3 N0 M0 PCa }\end{array}$ & $\begin{array}{l}\text { IPLND vs. ePLND } \\
\text { vs. sePLND }\end{array}$ & $\begin{array}{l}\text { ORP, RARP, } \\
\quad \text { LRP }\end{array}$ & $\begin{array}{c}\text { D’amico risk: } \\
\text {-Low } \\
\text {-Intermediate } \\
\text {-High }\end{array}$ & NA & CSS, BCR & - \\
\hline $\begin{array}{l}\text { Choo, at el. (2017). } \\
\text { Retrospective study. } \\
\text { (Meta-analysis). } \\
2004-2014 \text { (46). }\end{array}$ & $\begin{array}{l}\text { Seven studies } \\
\text { include to } \\
\text { oncology } \\
\text { outcomes results } \\
1095 \mathrm{p} \text {. }\end{array}$ & sPLND vs. ePLND & RARP, ORP & $\begin{array}{c}\text { D'amico risk: } \\
\text {-Intermediate } \\
\text {-High }\end{array}$ & NA & $\begin{array}{c}\text { BCR } \\
(H R 0.71,95 \% \\
\text { Cl } 0.56-0.90, p= \\
0.005)\end{array}$ & + \\
\hline $\begin{array}{l}\text { Preisser (2017). } \\
\text { Retrospective } \\
\text { 2004-2014 (44). } \\
\text { (SEER) database. }\end{array}$ & 28147 patients. & $\begin{array}{l}\text { IPLND }(75 \%) \text { vs. } \\
\text { ePLND }(24,8 \%)\end{array}$ & NA & $\begin{array}{c}\text { Gleason } \\
\text { - } \leq \text { 6: } 2238(8 \%) \\
\text { - 7: } 19374(68.8) \\
\text { - } \geq 8: 6535(23.2 \%) \\
\text { Intermediate risk } \\
-18942(67.3 \%) \\
\text { High risk }-9205 \\
(32.7 \%)\end{array}$ & $\begin{array}{c}\text { Median PSA } \\
\text { (IQR) } 6.5 \\
(4.8-10)\end{array}$ & $\begin{array}{c}\mathrm{N}^{\circ} \mathrm{LN}:>11 \text { nodes } \\
\text { removed improve } \\
\text { 6-years PCa- } \\
\text { specific survival } \\
(99.5 \% \text { vs } 98.1 \% \text {, } \\
\text { p: } 0,014) \\
\text { CSM-free:ePLND: } \\
\text { HR of } 0.52 \text { (C.I. } \\
\text { 0.30-0.89, P = } \\
0.017) .\end{array}$ & + \\
\hline $\begin{array}{l}\text { García-Perdomo et al. } \\
\text { (2018). } \\
\text { (Meta-analysis) (45). } \\
\text { Retrospective study. }\end{array}$ & $\begin{array}{c}4 \text { studies were } \\
\text { included to study } \\
\text { BRFS. }\end{array}$ & $\begin{array}{c}\text { Pca NOMO } \\
\text { sPLND vs. ePLND }\end{array}$ & $\begin{array}{c}\text { RAPR (1 } \\
\text { study), ORP } \\
\text { (3 studies) }\end{array}$ & $\begin{array}{c}\text { In Two studies: } \\
\text {-Low, intermediate and } \\
\text { high risk. } \\
\text { In other two studies: } \\
\text {-Intermediate and high } \\
\text { risk }\end{array}$ & NA & $\begin{array}{c}\text { BRFS } \\
\text { Favours ePLND } \\
\mathrm{HR}=0.62,95 \% \mathrm{Cl} \\
(0.36,0.87)\end{array}$ & + \\
\hline $\begin{array}{l}\text { Huele at al. (2018). } \\
\text { Retrospective study } \\
\text { (53). } \\
2000-2016\end{array}$ & $\begin{array}{c}228 \mathrm{p} . \\
\text { (9 patients were } \\
\text { excluded). } \\
\text { Roach formula: } \\
\text { 2/3 x prostate- } \\
\text { specific antigen } \\
\text { [PSA]+[Gleason } \\
\text { score - } 6] \times 10(75)\end{array}$ & $\begin{array}{c}\text { Staging PLND } \\
\text { before primary RT } \\
\text { in a single tertiary } \\
\text { care center }\end{array}$ & $\begin{array}{l}\text { ORP (50), } \\
\operatorname{LPP}(96), \\
\operatorname{RARP}(73)\end{array}$ & $\begin{array}{c}\text { Risk group } \\
\text { classification: } \\
\text {-Intermediate: } 41 \\
(18.8 \%) \\
\text {-High: } 126(57.8 \%) \\
\text {-Very high (locally } \\
\text { advanced): } 51(23.4 \%)\end{array}$ & NA & BCR, CSS, OS & - \\
\hline
\end{tabular}




$\begin{array}{lcc}\text { Furubayashi et al. } & \text { 348 patients } & \text { sPLND } \\ \text { (2019). Retrospective } & \text { T1-3 N0 M0 PCa. } & \text { (70.9\%,247/348) } \\ \text { single center study } & & \text { vs ePLND }\end{array}$

(47).

1998-2013.

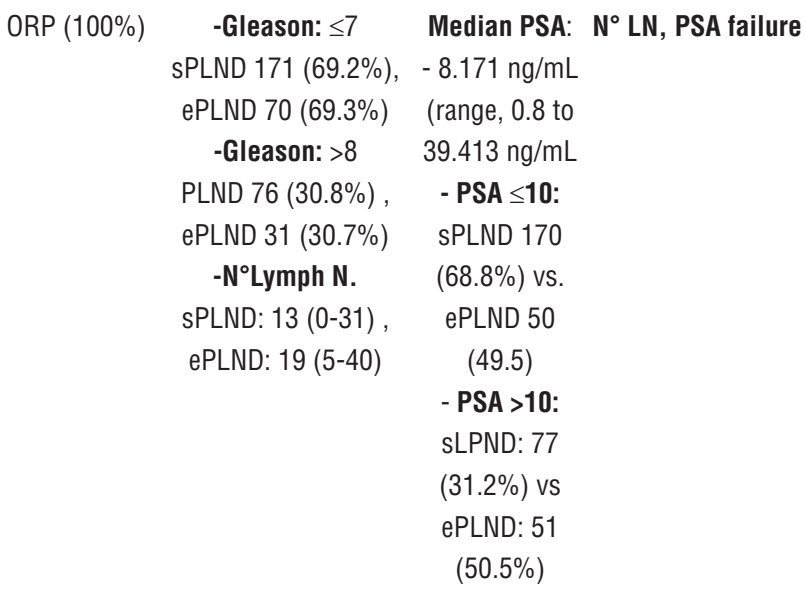

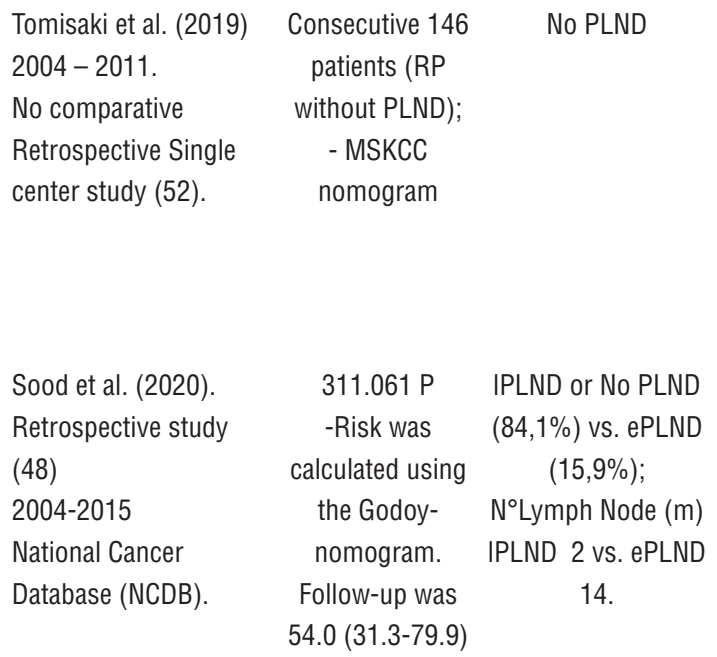

(48)
2004-2015

National Cancer

Database (NCDB).

calculated using the Godoy- $\quad N^{\circ}$ Lymph Node $(\mathrm{m})$ nomogram. IPLND 2 vs. ePLND

Follow-up was 14. $54.0(31.3-79.9)$ 


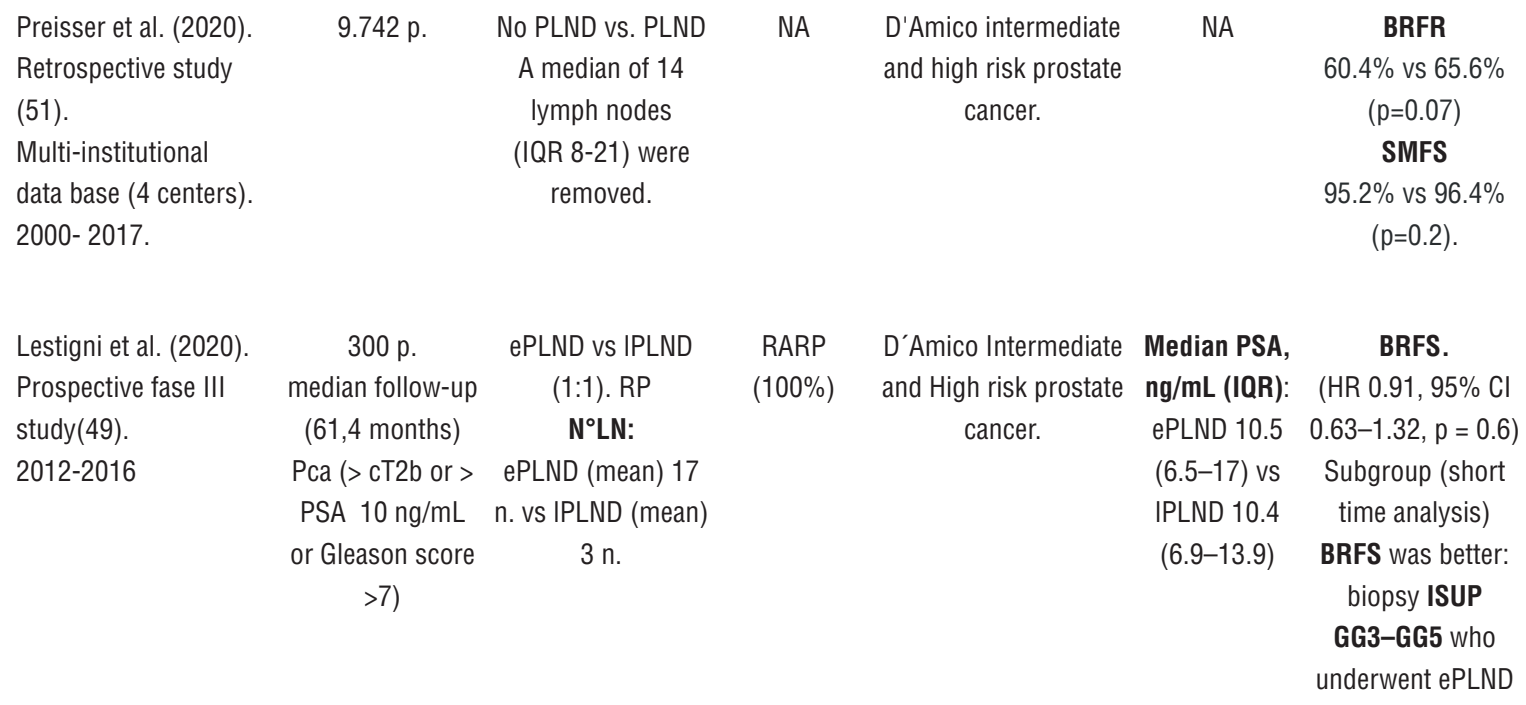

ASCO = American Society of Clinical Oncology; PLND = lymphadenectomy; $\mathbf{e P L N D}=$ extended PLND; IPLND = limited PLND; $\mathbf{S P L N D}=$ standart PLND; sePLND = super selective PLND; IQR = interquartile range; $\mathbf{N A}=$ not available; $\mathbf{B C R}=$ biochemical recurrence; $\mathbf{B F}=$ biochemical failure; $\mathbf{C S S}=$ cancer-specific survival; $\mathbf{O S}=$ Overall Survival; $\mathbf{C S M}-\mathbf{F}=$ Cancer specific metastasis free; $\mathbf{B R F}=$ Biochemical recurrence - free survival

Another two prospective randomized studies (NCT01555086) are being carried out to establish the impact of PLND on survival. The first of these is a German clinical trial that aims to show whether the extent of PLND could influence PSA progression over 5 years. While we continue to expect results, new data have not been presented since 2017. Currently, a second clinical trial has begun recruiting patients in Switzerland (NCT03921996), but it only comparing ePLND vs. no PLND in patients who undergo radical prostatectomy.

The impact of PLND on survival is still controversial and results of others prospective studies are eagerly awaited.

What are the outcomes of radical prostatectomy and plnd in node positive "only" disease?

The decision to perform treatment in advanced cancers is based on the principle of tumor volume reduction and local disease control. Patients with initial diagnosis of PCa and LNI represent 1.3$12 \%$ and they have a strong correlation with death (54). LNI in PCa represents a heterogeneous group of patients with different prognoses, depending on tumor grade and number of lymph nodes involved. A recent retrospective study done in the United States demonstrated an increased incidence of node-positi- ve PCa and this may be in part explained by a more frequent use of ePLND (55).

In the past, when LNI was found during the frozen section, radical prostatectomy was terminated (56), and the patient treated with hormones. Historically, patients diagnosed with PCa who had clinical LNI were treated as if they had systemic diseases. These patients were prescribed androgen deprivation therapy (ADT), even if only one lymph node was involved. More recently, Moschini et al. (57) retrospectively compared survival between patients with and without suspicious nodes on usual preoperative imaging studies. The authors found no differences in CSS and OS and concluded that suspicious nodes on preoperative imaging was not an absolute contraindication to RP in adequately selected and well-informed surgical candidates.

Georgios Gakis et al. (58) reported in 2014 the need to better define LNI on the grounds that there is an improved survival in patients with lymph node only metastasis who underwent radical prostatectomy and ePLND.

Several retrospective studies describe the benefits of PLND in patients with LNI only disease. In a retrospective study involving $315 \mathrm{pN} 1 \mathrm{PCa}$ patients, (59) the relationship between the number of lymph nodes removed and CSM was studied. The authors 
found a positive correlation between the number of lymph nodes removed and CSS (HR: 1.03, p: 0.05). Similar findings were reported by Elio Mazzone et al. (60) with added benefit on OS.

Nonetheless, the role of radical prostatectomy and PLND in patients with LNI remains unclear. Some authors argue that surgical treatment improves staging facilitating subsequent multimodal treatments (61) or postpone the onset of systemic therapy (62).

An institutional retrospective review evaluated predictors of clinical recurrence (CR) in patients undergoing radical prostatectomy with PLND. Approximately $80 \%$ had received neoadjuvant or adjuvant ADT. LNI and Gleason score $\geq 8$ were associated with an increased risk of CR. On the contrary, prognostic group 1-3 patients with only one increased nodule on preoperative imaging studies exhibited favorable oncological results with surgical therapy. The authors emphasized the need for adequate preoperative staging (63).

Although several studies showed encouraging results, the impact of PLND on survival in pelvic LNI only patients remains to be elucidated. However, progress was made in understanding the importance of adequate patient selection to identify those who would potentially benefit most from PLND.

\section{What are the risks of extend PLND?}

PLND during radical prostatectomy is usually well tolerated with a relatively low complication rate (64). Nonetheless, ePLND may be technically challenging and could lead to perioperative complications. Stone et al. reported a strikingly higher complication rate when they compared laparoscopic ePLND to laparoscopic IPLND (35.9\% vs. 2\%, p $<0.001$ ) (65).

Similarly, Briganti et al. reported a three-fold increase complication rate and longer hospital stay in patients undergoing ePLND compared to IPLND, and this was directly related to the number of LN removed (66).

Hospital readmissions were also higher in patients undergoing PLND during robot-assisted prostatectomy (RARP). Patients undergoing RARP and PLND had re-admission rates of 4.4\% in comparison to $0.8 \%$ of those without PLND (67). However,
Heidenreich et al. found that the frequency and severity of intra and postoperative complications did not differ significantly between limited and ePLND (9\% vs. 8.7\%, respectively) (68).

Asymptomatic lymphocele is the most frequent complication after PLND (69-71). Asymptomatic lymphocele detection rate on imaging studies varies from 27 to $61 \%(70,72)$. The incidence of symptomatic lymphocele is around $8 \%$ (73).

On occasions, lymphoceles may lead to deep vein thrombosis due to vein compression. If lymphoceles get infected, sepsis may duly follow requiring more aggressive treatment (74).

Capitanio et al. found in a prospective study of 552 patients, that the higher the number of lymph nodes removed ( $>20$ nodes) and the elder the patients (>65 years) the higher the likelihood of symptomatic lymphoceles after radical prostatectomy (74).

Improved surgical technique is key to diminish lymphocele rates. Stolzenburg, et al. proposed a technical modification consisting on suturing the cut end of the ventral parietal peritoneum back to the anterior and lateral pelvic side walls following ePLND to decrease the incidence of symptomatic lymphoceles, as shown in Figure-3 (75).

Another prospective study did not find significant differences in lymphocele rate when they compared the use of titanium clips to bipolar coagulation for the sealing of lymphatic vessels during RARP (76).

Figure 3 - Status following completion of four-point peritoneal flap fixation (P1, P2, P3, P4). The obturator nerves on both sides can be visualized (75).

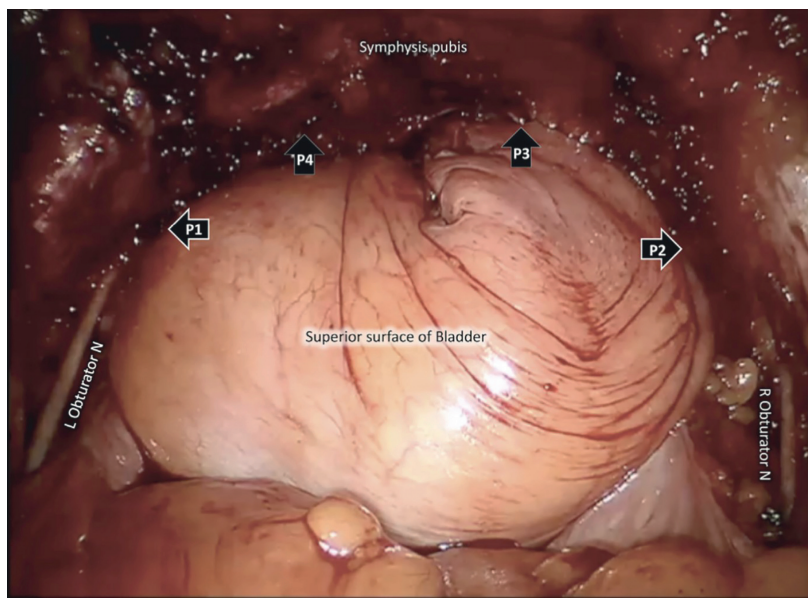


In sum, the more extended the PLND the higher the likelihood of perioperative complications, even in experienced hands. This should not refrain surgeons from performing ePLND when clinically indicated.

\section{CONCLUSIONS}

Despite advances in imaging and sentinel node methods, ePLND remains the most accurate method for staging intermediate and high-risk PCa. The impact of ePLND on BCR and survival is unclear yet. Select patients may benefit from ePLND but the challenge remains to identify them accurately. Only prospective randomized studies would answer the precise role of PLND in intermediate and high-risk pelvis confined PCa patients.

\section{CONFLICT OF INTEREST}

None declared.

\section{REFERENCES}

1. Rawla P. Epidemiology of Prostate Cancer. World J Oncol. 2019; 10:63-89.

2. Mottet N, Bellmunt J, Bolla M, Briers E, Cumberbatch MG, De Santis M, et al. EAU-ESTRO-SIOG Guidelines on Prostate Cancer. Part 1: Screening, Diagnosis, and Local Treatment with Curative Intent. Eur Urol. 2017; 71:618-29.

3. Schröder FH, Hugosson J, Roobol MJ, Tammela TL, Ciatto S, Nelen $\mathrm{V}$, et al. Screening and prostate-cancer mortality in a randomized European study. N Engl J Med. 2009; 360:1320-8.

4. Punnen S, Cooperberg MR. The epidemiology of high-risk prostate cancer. Curr Opin Urol. 2013; 23:331-6.

5. Ghodoussipour S, Cacciamani GE, Abreu ALC. Radical prostatectomy for high-risk prostate cancer | Opinion: NO. Int Braz J Urol. 2019; 45:428-34.

6. Briganti A, Larcher A, Abdollah F, Capitanio U, Gallina A, Suardi $N$, et al. Updated nomogram predicting lymph node invasion in patients with prostate cancer undergoing extended pelvic lymph node dissection: the essential importance of percentage of positive cores. Eur Urol. 2012; 61:480-7.

7. Porcaro AB, Corsi P, Inverardi D, Sebben M, Tafuri A, Processali $T$, et al. Prostate-specific antigen associates with extensive lymph node invasion in high-risk prostate cancer. Tumori. 2018; 104:307-11.
8. [No Authors]. Memorial Sloan Kettering Cancer Center. Dynamic prostate cancer nomogram:coefficients.[Internet]. Available at. <https://www.mskcc.org/nomograms/prostate/ pre_op/coefficients>

9. Hueting TA, Cornel EB, Somford DM, Jansen $H$, van Basten $J A$, Pleijhuis RG, et al. External Validation of Models Predicting the Probability of Lymph Node Involvement in Prostate Cancer Patients. Eur Urol Oncol. 2018; 1:411-7.

10. Hansen J, Rink M, Bianchi M, Kluth LA, Tian Z, Ahyai SA, et al. External validation of the updated Briganti nomogram to predict lymph node invasion in prostate cancer patients undergoing extended lymph node dissection. Prostate. 2013; 73:211-8.

11. Gandaglia G, Fossati N, Zaffuto E, Bandini M, Dell'Oglio P, Bravi $\mathrm{CA}$, et al. Development and Internal Validation of a Novel Model to Identify the Candidates for Extended Pelvic Lymph Node Dissection in Prostate Cancer. Eur Urol. 2017; 72:632-40.

12. NCCN Clinical practice guidelines in oncology: prostate cancer. National Comprehensive Cancer Network web site. 2017. [Internet]. Available at. <https://www.nccn.org/ professionals/ physician_gls/pdf/prostate.pdf>

13. Mohler JL, Armstrong AJ, Bahnson RR, D’Amico AV, Davis BJ, Eastham JA, et al. Prostate Cancer, Version 1.2016. J Natl Compr Canc Netw. 2016; 14:19-30.

14. Fossati N, Willemse PM, Van den Broeck T, van den Bergh RCN, Yuan CY, Briers E, et al. The Benefits and Harms of Different Extents of Lymph Node Dissection During Radical Prostatectomy for Prostate Cancer: A Systematic Review. Eur Urol. 2017; 72:84-109.

15. Hövels AM, Heesakkers RA, Adang EM, Jager GJ, Strum S, Hoogeveen $\mathrm{YL}$, et al. The diagnostic accuracy of CT and MRI in the staging of pelvic lymph nodes in patients with prostate cancer: a meta-analysis. Clin Radiol. 2008; 63:387-95.

16. Katz S, Rosen M. MR imaging and MR spectroscopy in prostate cancer management. Radiol Clin North Am. 2006; 44:723-34, viii.

17. Bellin MF, Beigelman C, Precetti-Morel S. Iron oxide-enhanced MR lymphography: initial experience. Eur J Radiol. 2000; 34:257-64.

18. Harisinghani MG, Saksena MA, Hahn PF, King B, Kim J, Torabi MT, et al. Ferumoxtran-10-enhanced MR lymphangiography: does contrast-enhanced imaging alone suffice for accurate lymph node characterization? AJR Am J Roentgenol. 2006; 186:144-8.

19. Anzai Y, Piccoli CW, Outwater EK, Stanford W, Bluemke DA, Nurenberg $P$, et al. Evaluation of neck and body metastases to nodes with ferumoxtran 10-enhanced MR imaging: phase III safety and efficacy study. Radiology. 2003; 228:777-88.

20. Pannu HK, Wang KP, Borman TL, Bluemke DA. MR imaging of mediastinal lymph nodes: evaluation using a superparamagnetic contrast agent. J Magn Reson Imaging. 2000; 12:899-904. 
21. Evangelista L, Briganti A, Fanti S, Joniau S, Reske S, Schiavina $\mathrm{R}$, et al. New Clinical Indications for (18)F/(11)C-choline, New Tracers for Positron Emission Tomography and a Promising Hybrid Device for Prostate Cancer Staging: A Systematic Review of the Literature. Eur Urol. 2016; 70:161-75.

22. Van den Bergh L, Lerut E, Haustermans K, Deroose CM, Oyen $\mathrm{R}$, Isebaert $\mathrm{S}$, et al. Final analysis of a prospective trial on functional imaging for nodal staging in patients with prostate cancer at high risk for lymph node involvement. Urol Oncol. 2015; 33:109.e23-31.

23. Morigi JJ, Stricker PD, van Leeuwen PJ, Tang R, Ho B, Nguyen Q, et al. Prospective Comparison of 18F-Fluoromethylcholine Versus 68Ga-PSMA PET/CT in Prostate Cancer Patients Who Have Rising PSA After Curative Treatment and Are Being Considered for Targeted Therapy. J Nucl Med. 2015; 56:1185-90.

24. Zang S, Shao G, Cui C, Li TN, Huang Y, Yao X, et al. 68Ga-PSMA-11 PET/CT for prostate cancer staging and risk stratification in Chinese patients. Oncotarget. 2017; 8:12247-58.

25. Kim SJ, Lee SW, Ha HK. Diagnostic Performance of Radiolabeled Prostate-Specific Membrane Antigen Positron Emission Tomography/Computed Tomography for Primary Lymph Node Staging in Newly Diagnosed Intermediate to High-Risk Prostate Cancer Patients: A Systematic Review and Meta-Analysis. Urol Int. 2019; 102:27-36.

26. Maurer T, Gschwend JE, Rauscher I, Souvatzoglou M, Haller B, Weirich G, et al. Diagnostic Efficacy of (68)Gallium-PSMA Positron Emission Tomography Compared to Conventional Imaging for Lymph Node Staging of 130 Consecutive Patients with Intermediate to High Risk Prostate Cancer. J Urol. 2016; 195:1436-43.

27. Metser U, McVey R, Ferguson SE, Halankar J, Bernardini MQ. Intraoperative lymph node evaluation using 18 F-FDG and a hand-held gamma probe in endometrial cancer surgery--a pilot study. Eur J Gynaecol Oncol. 2016; 37:362-6.

28. Vermeeren L, Valdés Olmos RA, Klop WM, Balm AJ, van den Brekel MW. A portable gamma-camera for intraoperative detection of sentinel nodes in the head and neck region. J Nucl Med. 2010; 51:700-3.

29. Chondrogiannis S, Ferretti A, Facci E, Marzola MC, Rampin L, Tadayyon S, et al. Intraoperative hand-held imaging $\gamma$-camera for sentinel node detection in patients with breast cancer: feasibility evaluation and preliminary experience on 16 patients. Clin Nucl Med. 2013; 38:e132-6. Erratum in: Clin Nucl Med. 2014; 39:417.
30. Chung YA, Kim SH, Sohn HS, Chung SK, Rhim CC, Namkoong SE. Usefulness of lymphoscintigraphy and intraoperative gamma probe detection in the identification of sentinel nodes in cervical cancer. Eur J Nucl Med Mol Imaging. 2003; 30:1014-7.

31. Heller S, Zanzonico P. Nuclear probes and intraoperative gamma cameras. Semin Nucl Med. 2011; 41:166-81.

32. Wawroschek F, Vogt $H$, Weckermann D, Wagner T, Harzmann R. The sentinel lymph node concept in prostate cancer first results of gamma probe-guided sentinel lymph node identification. Eur Urol. 1999; 36:595-600.

33. van der Poel HG, Wit EM, Acar C, van den Berg NS, van Leeuwen FWB, Valdes Olmos RA, et al. Sentinel Node Prostate Cancer Consensus Panel Group members. Sentinel node biopsy for prostate cancer: report from a consensus panel meeting. BJU Int. 2017; 120:204-211.

34. Wit EMK, Acar C, Grivas N, Yuan C, Horenblas S, Liedberg F, et al. Sentinel Node Procedure in Prostate Cancer: A Systematic Review to Assess Diagnostic Accuracy. Eur Urol. 2017; 71:596-605.

35. Acar C, Kleinjan GH, van den Berg NS, Wit EM, van Leeuwen FW, van der Poel HG. Advances in sentinel node dissection in prostate cancer from a technical perspective. Int J Urol. 2015; 22:898-909.

36. Briganti A, Chun FK, Salonia A, Gallina A, Zanni G, Scattoni $V$, et al. Critical assessment of ideal nodal yield at pelvic lymphadenectomy to accurately diagnose prostate cancer nodal metastasis in patients undergoing radical retropubic prostatectomy. Urology. 2007; 69:147-51.

37. Briganti A, Chun FK, Salonia A, Zanni G, Gallina A, Dehò F, et al. A nomogram for staging of exclusive nonobturator lymph node metastases in men with localized prostate cancer. Eur Urol. 2007; 51:112-9; discussion 119-20.

38. Bader P, Burkhard FC, Markwalder R, Studer UE. Is a limited lymph node dissection an adequate staging procedure for prostate cancer? J Urol. 2002; 168:514-8; discussion 518.

39. Barth PJ, Gerharz EW, Ramaswamy A, Riedmiller H. The influence of lymph node counts on the detection of pelvic lymph node metastasis in prostate cancer. Pathol Res Pract. 1999; 195:633-6.

40. Abdollah F, Sun M, Thuret R, Jeldres C, Tian Z, Briganti A, et al. Lymph node count threshold for optimal pelvic lymph node staging in prostate cancer. Int J Urol. 2012; 19:645-51.

41. Heidenreich A, OhImann CH, Polyakov S. Anatomical extent of pelvic lymphadenectomy in patients undergoing radical prostatectomy. Eur Urol. 2007; 52:29-37. 
42. Weingärtner K, Ramaswamy A, Bittinger A, Gerharz EW, Vöge $D$, Riedmiller $\mathrm{H}$. Anatomical basis for pelvic lymphadenectomy in prostate cancer: results of an autopsy study and implications for the clinic. J Urol. 1996; 156:1969-71.

43. Mattei A, Fuechsel FG, Bhatta Dhar N, Warncke SH, Thalmann GN, Krause T, Studer UE. The template of the primary lymphatic landing sites of the prostate should be revisited: results of a multimodality mapping study. Eur Urol. 2008; 53:118-25.

44. Preisser F, Bandini M, Marchioni M, Nazzani S, Tian Z, Pompe RS, et al. Extent of lymph node dissection improves survival in prostate cancer patients treated with radical prostatectomy without lymph node invasion. Prostate. 2018; 78:469-75.

45. García-Perdomo HA, Correa-Ochoa JJ, Contreras-García R, Daneshmand S. Effectiveness of extended pelvic lymphadenectomy in the survival of prostate cancer: a systematic review and meta-analysis. Cent European J Urol. 2018; 71:262-9.

46. Choo MS, Kim M, Ku JH, Kwak C, Kim HH, Jeong CW. Extended versus Standard Pelvic Lymph Node Dissection in Radical Prostatectomy on Oncological and Functional Outcomes: A Systematic Review and Meta-Analysis. Ann Surg Oncol. 2017; 24:2047-54.

47. Furubayashi N, Negishi T, Uozumi T, Shiraishi K, Taguchi K, Shimokawa M, et al. Eliminating microscopic lymph node metastasis by performing pelvic lymph node dissection during radical prostatectomy for prostate cancer. Mol Clin Oncol. 2020; 12:104-10.

48. Sood A, Keeley J, Palma-Zamora I, Dalela D, Arora S, Peabody J0, et al. Extended pelvic lymph-node dissection is independently associated with improved overall survival in patients with prostate cancer at high-risk of lymph-node invasion. BJU Int. 2020; 125:756-8.

49. Lestingi JFP, Guglielmetti GB, Trinh QD, Coelho RF, Pontes $\mathrm{J} J \mathrm{r}$, Bastos DA, et al. Extended Versus Limited Pelvic Lymph Node Dissection During Radical Prostatectomy for Intermediate- and High-risk Prostate Cancer: Early Oncological Outcomes from a Randomized Phase 3 Trial. Eur Urol. 2020: S0302-2838; 30941-6.

50. Chen J, Wang Z, Zhao J, Zhu S, Sun G, Liu J, et al. Pelvic lymph node dissection and its extent on survival benefit in prostate cancer patients with a risk of lymph node invasion $>5 \%$ : a propensity score matching analysis from SEER database. Sci Rep. 2019; 9:17985.
51. Preisser F, van den Bergh RCN, Gandaglia G, Ost P, Surcel $\mathrm{Cl}$, Sooriakumaran P, et al. Effect of Extended Pelvic Lymph Node Dissection on Oncologic Outcomes in Patients with D'Amico Intermediate and High Risk Prostate Cancer Treated with Radical Prostatectomy: A Multi-Institutional Study. J Urol. 2020; 203:338-43.

52. Tomisaki I, Ikuta H, Higashijima K, Onishi R, Minato A, Fujimoto N. Oncological Outcome After Radical Prostatectomy without Pelvic Lymph Node Dissection for Localized Prostate Cancer: Follow-up Results in a Single Institution. Cancer Invest. 2019; 37:524-30.

53. Van Huele A, Poelaert F, Fonteyne V, Decaestecker K, Ost P, Lumen N. Pelvic lymph node dissection in prostate cancer staging: evaluation of morbidity and oncological outcomes. Acta Chir Belg. 2019; 119:103-9.

54. Siegel RL, Miller KD, Jemal A. Cancer statistics, 2018. CA Cancer J Clin. 2018; 68:7-30.

55. Taylor MA, Alemozaffar M, Master VA, Sanda MG, Filson CP. Rise in Node-Positive Prostate Cancer Incidence in Context of Evolving Use and Extent of Pelvic Lymphadenectomy. Clin Genitourin Cancer. 2019; 17:e494-e504.

56. Gerber GS, Thisted RA, Chodak GW, Schroder FH, Frohmuller $\mathrm{HG}$, Scardino PT, et al. Results of radical prostatectomy in men with locally advanced prostate cancer: multi-institutional pooled analysis. Eur Urol. 1997; 32:385-90.

57. Moschini M, Briganti A, Murphy CR, Bianchi M, Gandaglia G, Montorsi F, et al. Outcomes for Patients with Clinical Lymphadenopathy Treated with Radical Prostatectomy. Eur Urol. 2016; 69:193-6.

58. Gakis G, Boorjian SA, Briganti A, Joniau S, Karazanashvili G, Karnes RJ, et al. The role of radical prostatectomy and lymph node dissection in lymph node-positive prostate cancer: a systematic review of the literature. Eur Urol. 2014; 66:191-9.

59. Abdollah F, Gandaglia G, Suardi N, Capitanio U, Salonia A, Nini A, et al. More extensive pelvic lymph node dissection improves survival in patients with node-positive prostate cancer. Eur Urol. 2015; 67:212-9.

60. Mazzone E, Preisser F, Nazzani S, Tian Z, Bandini M, Gandaglia G, et al. The Effect of Lymph Node Dissection in Metastatic Prostate Cancer Patients Treated with Radical Prostatectomy: A Contemporary Analysis of Survival and Early Postoperative Outcomes. Eur Urol Oncol. 2019; 2:541-8. 
61. Motterle G, Ahmed ME, Andrews JR, Karnes RJ. The Role of Radical Prostatectomy and Lymph Node Dissection in Clinically Node Positive Patients. Front Oncol. 2019; 9:1395.

62. Fantin JPP, Furst MCB, Tobias-Machado M, Muller RL, Machado RD, Santos AC, et al. Role of salvage lymph node dissection in patients previously treated for prostate cancer: systematic review. Int Braz J Urol. 2021;47:484-94.

63. Gandaglia G, Soligo M, Battaglia A, Muilwijk T, Robesti D, Mazzone E, et al. Which Patients with Clinically Nodepositive Prostate Cancer Should Be Considered for Radical Prostatectomy as Part of Multimodal Treatment? The Impact of Nodal Burden on Long-term Outcomes. Eur Urol. 2019; 75:817-25.

64. Keegan KA, Cookson MS. Complications of pelvic Iymph node dissection for prostate cancer. Curr Urol Rep. 2011; 12:203-8.

65. Stone NN, Stock RG, Unger P. Laparoscopic pelvic lymph node dissection for prostate cancer: comparison of the extended and modified techniques. J Urol. 1997; 158:1891-4.

66. Briganti A, Chun FK, Salonia A, Suardi N, Gallina A, Da Pozzo LF, et al. Complications and other surgical outcomes associated with extended pelvic lymphadenectomy in men with localized prostate cancer. Eur Urol. 2006; 50:1006-13.

67. Sebben M, Tafuri A, Shakir A, Pirozzi M, Processali T, Rizzetto $\mathrm{R}$, et al. The impact of extended pelvic lymph node dissection on the risk of hospital readmission within 180 days after robot assisted radical prostatectomy. World $\mathrm{J}$ Urol. 2020; 38:2799-809.

68. Heidenreich A, Varga Z, Von Knobloch R. Extended pelvic lymphadenectomy in patients undergoing radical prostatectomy: high incidence of lymph node metastasis. J Urol. 2002; 167:1681-6.

69. Solberg A, Angelsen A, Bergan U, Haugen OA, Viset T, Klepp 0 . Frequency of lymphoceles after open and laparoscopic pelvic lymph node dissection in patients with prostate cancer. Scand J Urol Nephrol. 2003; 37:218-21.
70. Spring DB, Schroeder D, Babu S, Agee R, Gooding GA Ultrasonic evaluation of lymphocele formation after staging Iymphadenectomy for prostatic carcinoma. Radiology. 1981; 141:479-83.

71. Musch M, Klevecka V, Roggenbuck U, Kroepfl D. Complications of pelvic lymphadenectomy in 1,380 patients undergoing radical retropubic prostatectomy between 1993 and 2006. J Urol. 2008; 179:923-8; discussion 928-9.

72. Zorn KC, Katz MH, Bernstein A, Shikanov SA, Brendler CB, Zagaja GP, et al. Pelvic lymphadenectomy during robotassisted radical prostatectomy: Assessing nodal yield, perioperative outcomes, and complications. Urology. 2009; 74:296-302.

73. Ploussard G, Briganti A, de la Taille A, Haese A, Heidenreich A, Menon M, Sulser T, Tewari AK, Eastham JA. Pelvic lymph node dissection during robot-assisted radical prostatectomy: efficacy, limitations, and complications-a systematic review of the literature. Eur Urol. 2014; 65:7-16.

74. Capitanio U, Pellucchi F, Gallina A, Briganti A, Suardi N, Salonia $A$, et al. How can we predict lymphorrhoea and clinically significant lymphocoeles after radical prostatectomy and pelvic lymphadenectomy? Clinical implications. BJU Int 2011; 107:1095-101.

75. Stolzenburg JU, Arthanareeswaran VKA, Dietel A, Franz T, Liatsikos E, Kyriazis I, et al. Four-point Peritoneal Flap Fixation in Preventing Lymphocele Formation Following Radical Prostatectomy. Eur Urol Oncol. 2018; 1:443-8.

76. Grande P, Di Pierro GB, Mordasini L, Ferrari M, Würnschimmel $\mathrm{C}$, Danuser $\mathrm{H}$, et al. Prospective Randomized Trial Comparing Titanium Clips to Bipolar Coagulation in Sealing Lymphatic Vessels During Pelvic Lymph Node Dissection at the Time of Robot-assisted Radical Prostatectomy. Eur Urol. 2017; 71:155-8.
Correspondence address:

Luciano Gabriel Haiquel, MD

Department of Urology,

Sanatorio Las Lomas de San Isidro, Diego Carman, 555

San Isidro, Buenos Aires, 1642, Argentina

Telephone: +11 153 334-7347

E-mail: lucianohaiquel@gmail.com 